\title{
Hoofstuk 6 \\ Die verbreiding van die \\ Calvinisme in Nederland
}

\subsection{Die beginjare}

Soos reeds aangetoon, het Lutherse invloede vanaf die vroeë twintigerjare van die sestiende eeu al in Nederland deurgewerk. Die algemene Hervormde gesindheid is egter geskep deur die Bybelse Humaniste en die Sakramentariërs. Die algemene verwerping van die Rooms-Katolieke godsdiens, wat in baie opsigte 'n mengsel van vormgodsdiens en bygeloof was, is ook veroorsaak deur die feit dat die Rooms-Katolieke priesters bitter min gedoen het om hulle lidmate se godsdienstige behoeftes te bevredig. In hierdie situasie het die verskillende Doperse strominge bygedra om 'n verwarrende situasie te skep.

Dit is in hierdie situasie wat in 1543 'n pamflet van Calvyn nogal opslae maak. Die pamflet dra die titel, Petit traicte, monstrant que c'est que doit faire un homme fidele cougnoissant la verité de l'evangile: quand il est entre les papistes ('n klein verhandeling wat aantoon wat 'n gelowige man, wat die waarheid van die evangelie ken, moet doen wanneer hy onder die Papiste verkeer). Dit is om meer as een rede 'n belangrike pamflet, omdat dit ' $n$ saak aangesny het wat destyds van lewensbelang was, want die Papiste (of Rooms-Katolieke) het elke afwyking van die Rooms-Katolieke geloof swaar gestraf. Calvyn se argument hier is dat die gelowige te alle tye aan God gehoorsaam moet wees, al sou dit vervolging en die doodstraf beteken. Daarom verwerp hy die opvatting van sommige mense wat in die openbaar voorgegee het dat hulle nog Rooms-Katolieke gelowiges is, terwyl hulle in die geheim die Rooms-Katolieke leer reeds verwerp het. Hier stel Calvyn dan die volgende belangrike saak: "n Mens kan my vra watter raad ek wil gee aan 'n gelowige wat só in 'n Egipte of in 'n Babel moet bly waar hy nie toegelaat word om God suiwer te aanbid nie, maar waar hy, volgens die algemene gebruik, gedwing word om hom in slegte omstandighede te skik.' As antwoord op hierdie situasie beveel Calvyn aan dat so 'n gelowige maar die land moet verlaat. As dit nie moontlik is nie, rus die plig op die gelowige om hom van alle afgodery te distansieer, terwyl hy in 'n Rooms-Katolieke 
gemeenskap woon. Calvyn is baie skerp in sy afwysing van pogings om in 'n soort kompromissituasie te probeer lewe.

Miskien kan net daarop gewys word dat Calvyn hierdie argumente herhaal en aanvul in sy pamflet teen die Nikodemiete van 1544 . Hierdie aanwysings van Calvyn om eerder die land te verlaat as om in 'n Rooms-Katolieke land te bly en gedwing te word tot afgodery, gee ook aanleiding daartoe dat baie mense na Europa vlug om so die Rooms-Katolieke vervolging in hulle eie vaderland te ontsnap.

In 1544 gaan 'n afvaardiging van Tournai, 'n stadjie in die suide van die Nederlande, na Genève met die versoek om 'n Calvinistiese predikant na Nederland te stuur. Dit is gedoen, omdat die afvaardiging die Hervormingsbeweging wou bewaar, enersyds van die bygeloof van die Rooms-Katolieke, en andersyds van die radikalisme van die Dopers. Die antwoord was dat Pierre Brully na die Suid-Nederlandse Franssprekende provinsies gestuur is om die Woord te verkondig, die sakramente te bedien en die organisasie van die kerk ter hand te neem. Die rede dat Genève vir hulp gevra is, was dat die Calvinistiese predikante nie alleen goed opgelei was nie, maar terselfdertyd standvastig genoeg was om die Hervorming in geordende bane te lei.

Dit is opvallend dat die Calvinistiese predikante deur die kwaliteit van hulle prediking en hulle onbesproke lewenswandel daarin geslaag het om die Hervormingsbeweging in Nederland vir die Calvinisme te wen. Die gang van sake was egter nie so enkelvoudig nie. Pierre Brully word in 1545 gevang en tereggestel. Die volgende predikante wat vanuit Genève gestuur is, was Evrard Erail en Arnold Blanc wat in 1557 in Antwerpen aankom. In 1558 vlug Erail na London, terwy! Blanc dit skaars ses maande uithou. Dit bring mee dat lekepredikers na vore tree soos Gaspard van der Heyden wat as jong seun by die gemeente Antwerpen aansluit. In 1551, nadat die plaaslike predikant, Jan van Ostende, tereggestel is, neem Van der Heyden die leiding oor, terwyl hy as skoenmaker in sy lewenstog voorsien. Eers in 1555 , wanneer die gemeente kans sien om hom te onderhou, reis hy na Emden om bevestig te word. So het Jean de Lannoy eers ouderling geword te Tournai en dan 'n assistent van Guido de Brès. Daar was ook lekepredikers wat almal kleiner kringe om hulle heen versamel het vir Bybellesing, kategese, die sing van Psalms en gebed. Hierdie eerste 'huisgemeentes' wat so vergader het, asook die byeenkomste wat in die openbaar gehou is, was daarop gerig om nuwe lidmate te werf. Die belydende lidmate het gewoonlik in die geheim byeengekom en hulle byeenkomste is alleen bygewoon deur lidmate wat al sterk gestaan het en 'n eed afgelê het om alles te doen om die kerk te bewaar en uit te bou. Hierdie byeenkomste was beperk tot ongeveer tien mense. In Tournai het Guido de Brès nie anders nie as in die 
aande derglike byeenkomste bygewoon waar hy dan gepreek het. Die klem het voortdurend op die prediking geval.

Dit is opvallend hoe min bevestigde predikante daar was. In die gebied Tournai-Lille-Valenciennes was De Brès tot 1563 die enigste bevestigde predikant. Behalwe in Antwerpen, waar daar meer predikante was, was dit die lekepredikers wat kategese moes gee en preek.

Die werfkrag van die beweging was groot. As voorbeeld kan Paul Chevalier, 'n Rooms-Katolieke priester te Tournai genoem word, wat deur een van De Brès se assistente bekeer is. Ná opleiding deur Jean de Lannoy word hy predikant te Valenciennes. So is Adrianus Saravia deur Jacques Taffin bearbei en, nadat hy uit die klooster ontsnap het, het hy ná opleiding predikant te Brussel geword.

\subsection{Eerste pogings tot organisasie}

Sodra daar êrens voldoende lidmate was, is 'n kerkraad gekies wat die werk verder gereël het. Vanweë die gevaar van vervolging het die gemeentes skuilname gebruik: Tournai ofte wel Doornik was La Palme, Armentiéres was Le Bouton, Antwerpen was La Vigne en Gent was La Glaive.

Vanuit die kerkraadsvergaderings is provinsiale sinodes saamgestel wat in die periode 1563-1565 reëlmatig vergader en rigting gegee het aan die prediking, kategese en die opleiding van bekeerlinge. Met die samestelling en besluitneming is die Franse kerkordelike reëlings gevolg en die gebruike in die Calvinistiese kerke. Deur middel van hierdie sinodes is getrag om 'n hegte organisasie te bou en daar is veral skerp gelet op die Rooms-Katolieke of Doperse afwykende menings. Daarom moes nie net die predikante nie, maar ook alle ouderlinge en diakens die Nederlandse Geloofsbelydenis onderskryf. Hierdie belydenisskrif is opgestel in 1561 en in 1563 by 'n provinsiale sinode van Armentiéres as belydenisskrif van die kerk aanvaar. In 1565 word besluit om die belydenis aan die begin van elke sinode te lees en dit dan beskikbaar te stel vir hersiening. Interessant is dat in hierdie vroeë jare die predikante en kerkrade van Antwerpen en đié in Vlaandere noue betrekkinge gehou het met London en Emden en in 'n sekere sin hulleself onder hulle sorg geplaas het. Die Franssprekende predikante het weer met Genève gekorrespondeer en daar hulp en steun gesoek. Die verskil het in hierdie beginjare nie juis saak gemaak nie, want die organisasie was nog taamlik los, hoewel die aanvaarding van 'n nasionale belydenis en die bestaan van sinodes tog al 'n duidelike organisatoriese band geskep het. Daarby het dit die Calviniste in Nederland die sekerheid gegee dat hulle deel was van 'n groot en breë Europese beweging. So is die weg gebaan tot die vestiging van 'n landskerk, enersyds deur prediking en kategese in die kleiner groep, 
en andersyds deur die hou van sinodes, die kommunikasie met mekaar en met buitelandse kerke.

Tot op dié stadium het die Calviniste enige openlike konfrontasie met die owerhede vermy. Dit was Adriaan van Haemstede wat in 1557 in die openbaar begin preek in Antwerpen omdat hy die ondergrondse optrede nie meer wou billik nie. In 1558 doen hy dit weer sodat die owerhede met 'n onderdrukkingsaksie begin wat Gaspard van der Heyden verplig om na Duitsland te vlug. Van Haemstede gaan hiermee voort totdat hy in 1559 moet vlug. Sy voorbeeld word in 1562 deur Ghislain Damman, ' $n$ lekeprediker, gevolg. Hoewel Damman tydens sy opelug prediking beskerm word, word baie lede van sy gehoor gearresteer.

In September 1561 het 'n diaken, Robert Dufour, omtrent driehonderd lidmate deur die strate van Valenciennes gelei, terwyl hulle Psalms sing. Hoewel De Brès en sy assistent Jean de Lannoy die demonstrasie afkeur, kan hulle dit nie keer nie. Toe 'n groot aantal van hulle gearresteer is, skryf De Brès sy beroemde brief aan die koning en gooi dit saam met 'n kopie van die Nederlandse Geloofsbelydenis oor die kasteelmuur om sodoende die owerhede te oorreed om die vervolginge te staak. Dit gebeur egter nie en De Brès moet na Frankryk vlug.

Hoewel daar nog verdere openbare demonstrasies en preke was, slaag die owerhede tog daarin om in die loop van die tyd hierdie bewegings te onderdruk en om die Calvinistiese kerk te dwing om weer ondergronds te gaan. Hier word dit duidelik dat die kerk as 'n geheel nog nie sterk genoeg was om 'n konfrontasie met die owerheid te weerstaan nie - dit ook omdat die Calviniste nog nie daarin geslaag het om leidinggewende mense in die gemeenskap te werf om hulle te steun nie. Hulle steun het hoofsaaklik in die geledere van die gewone man gelê.

Hierdie steun word egter uitgebrei deur die merkwaardige moed en voorbeeldigheid van die Calvinistiese martelare. Met merkwaardige insig het die Calviniste daarin geslaag om Bybelse parallelle te vind om daarmee aan te dui dat hulle die ware gelowiges is. Dit is veral gedoen deur Jean Crespin se Histoire des Martyrs van 1554 en Adriaan van Haemstede se Martyrologie van 1559. Juis in hulle lyding en dood het die Calvinistiese predikante en gelowiges 'n bewys gesien dat God hulle uitverkies het en dat hulle wettige geroepenes is. Een van die martelare het dit soos volg gestel: ‘[D]t is hoe ek myself troos...ek oorweeg nie alleen met sorg alles wat met my gaan gebeur nie, maar ook hoe die naam van die Here grootgemaak en geeer en geprys sal word deur my standvastigheid en dood. Ek is nie baie seker van myself nie...maar ek is ten volle verseker van die beloftes van Christus' (my vertaling).

So gebeur dit dat, hoewel daar in hierdie beginjare maar net ' $n$ oppervlakkige 
organisasie gebou is en die predikante boonop maar min is, daar tog voorbereidende werk gedoen is wat standgehou het.

Die volgende boeke kan hier nagelees word as agtergrondmateriaal:

Dankbaar, W F 1957. Calvijn zijn weg en werk. Nijkerk: Callenbach.

De Greef, W 1989. Johannes Calvijn zijn werk en geschriften. Kampen: Uitgeverij De Groot Goudriaan.

McNeill, John T 1967. The history and character of Calvinism. New York: Oxford University Press.

Oberman, H A 1988. De erfenis van Calvijn: Grootheid en grenzen. Kampen: Kok. Parker, T H L 1975. John Calvin: A biography. London: J M Dent \& Sons Ltd. Van Campen, M 1988. Leven uit Gods beloften: Een centraal thema bij Johannes Calvijn. Kampen: Uitgeverij De Groot Goudriaan.

\section{Ekskurs: Die Nederlandse Geloofsbelydenis}

Die opsteller van die Nederlandse Geloofsbelydenis was Guido de Brès (15521567). Gebore te Mons word hy veral deur sy diep-godsdienstige moeder in sy jeugjare beïnvloed. Aanvanklik was hy bestem om 'n glasskilder te word, maar kry dan 'n Bybel in die hande. Sy sorgvuldige lees van die Bybel laat hom die Rooms-Katolieke Kerk verlaat om ansluiting by die Reformasie te vind.

In 1548 verlaat hy, onder die druk van vervolginge, sy vaderstad en gaan na Engeland waar hy hom veral met die studie van die teologie besig hou. In 1552 keer hy terug en vestig hom te Rijssel. Daar begin hy met evangelieprediking. Hy werk daar totdat hernude vervolging hom dwing om Rijssel te verlaat. Dan swerf hy rond: Eers is hy in Gent, dan in Frankfort am Main waar hy onder andere Calvyn ontmoet. Daar voer hy nog twisgesprekke met Anabaptiste. Vandaar reis hy na Lausanne en Genève om sy teologiese studies voort te sit.

De Brès se eerste werk, wat hy nog te Rijssel skrywe, is getitel, Le Baston de la Foy Crestienne, Livres très utile a tout Crestiens pour s'armer contre les ennemys de l'evangile et pour aussi cognoistre l'ancienneté de nostre saincte foy, et de la vraye Eglise. Die werk wat in 1555 verskyn is 'n versameling aanhalings uit die werke van die vroeë Kerkvaders om daarmee die regmatigheid van die Calvinistiese leer teenoor die Rooms-Katolieke Kerk te bevestig. Hierdie werk getuig van 'n verbasende kennis van die Patristiek. Die werk het baie aansien geniet en is verskillende male herdruk.

In 1559 keer hy terug na Nederland en tree in Augustus 1560 in die huwelik. Nou woon en werk hy in Doornik en omgewing en bou hy aan die ondergrondse 
kerk. Geleidelik word De Brès een van die spilpunte waaromheen die Hervorming gebou word.

De Brès moet Doornik verlaat met die verskerpte vervolging, nadat 'n groep Hervormers in die strate van Doornik Psalms gesing het. Tydens hierdie vervolginge word in die nag van 1 November 1561 'n pakkie, bestem vir die landvoogdes, oor die muur van die kasteel van Doornik gegooi. Die brief, gerig aan Koning Filips II, bevat ' $n$ verdediging van die vervolgdes, terwyl die ingeslote geloofsbelydenis hulle geloof omskrywe. Die versoek het geen positiewe gevolg gehad nie, behalwe dat die vervolging verskerp is. Beide die brief en die geloofsbelydenis is deur De Brès opgestel. Vanweë die vervolgings wyk De Brès uit na Sedan waar hy tot 1566 werksaam is. Daarvandaan het hy Nederland verskillende male besoek en in 1564 samesprekings gevoer met prins Willem van Oranje oor sy plan om samewerking tussen die Lutherane en Calviniste te kry.

In 1566 word De Brès na Antwerpen beroep en gaan hy dan van daar na Valenciennes. Aangesien Valenciennes toe al openlik Protestants was, preek De Brès reëlmatig in die St Janskerk aldaar. Valenciennes word egter deur die Rooms-Katolieke owerhede aangeval en in 1567 moet die stad oorgee. Onder diegene wat gevang word is De Brès, en saam met sy ampsgenoot Peregrin de la Grange word hy op 31 Mei 1567 in Valenciennes tereggestel. De Brès was 'n geleerde predikant en 'n oortuigde Calvinis en hy het sy lewe lank met Calvyn kontak gehou. Sy werk in die Suidelike Nederlande en in Noord-Frankryk het die Hervorming 'n groot stoot gegee en sy ywer en prediking het ' $n$ blywende indruk gemaak. Nog een ander werk van hom is gepubliseer, naamlik' $n$ aanval op die Anabaptisme. Gepubliseer in 1565 is 'n Nederlandse vertaling in 1570 gepubliseer met die titel, De Wortel, den oorspronck ende het fundament der Wederdooperen oft herdooperen van onsen tijde. Met overvloedige wederlegginghe der sondelincst angumenten, door dewelcke sij ghewoon zijn de gemeijnte onses Heeren J C te beroeren ende den eenvuldige te verleyden. As hierdie werk van De Brès gelees word en ook sy ander geskrifte, dan is dit duidelik dat die Nederlandse Geloofsbelydenis inderdaad deur 'n bekwame, Calvinistiese teoloog. opgestel is.

Die Nederlandse Geloofsbelydenis wat in 1561 deur De Brès opgestel is, was in Frans geskrywe. Die belydenis is in dieselfde jaar herdruk, weer eens in 1562 en dan weer in 1565 en ook in 1566 . In 1611 word weer 'n uitgawe besorg en dié uitgawe word in 1619 by Dordt hersien, waar die finale teks vasgestel is. Die oudste Nederlandse vertaling dateer terug na 1562, terwyl betreklik vroeg, in 1566, 'n Latynse vertaling gemaak is, waarskynlik deur Beza in die Harmonia Confessionum van 1581. Die finale teks is by Dordt in 1619 vasgelè, waar 'n kommissie oor die saak moes handel. Daar is ook 'n Latynse vertaling gemaak. 
Die Nederlandse Geloofsbelydenis (hierna NGB) wat deur De Brès as verweerskrif en apologie opgestel is, soos blyk uit die brief gerig aan Filips II wat dit vergesel het, is nie dadelik as 'n belydenisskrif gebruik nie. In 1563 bepaal die Sinode van Armentiéres dat die ouderlinge en diakens die NGB moet onderteken. Dit beteken egter nie dat die NGB op daardie stadium al 'n bindende gesag gehad het nie, want in Antwerpen in 1565 word die belydenisskrif onderteken om daarmee slegs die onderlinge eenheid te beklemtoon.

By Wesel word in 1568 besluit om elke aankomende predikant te vra 'of hy in alles overeenkomt met de leer die in de kerk opentlijk wordt onderhouden en vervat is in de belijdenis [dan word sowel die Franse as die Nederlandse Geloofsbelydenis genoem] en die Kategismus' (art 18).

Emden se sinode van 1571 besluit in artikel 2 om die belydenis te onderteken 'om de eendrachtigheid in de leer tussen de Nederlandse kerken te bewijzen'. Dus is die NGB nie dadelik as norm en reël van die prediking aanvaar nie.

Die NGB was 'n verwerking van die Franse Geloofsbelydenis wat in 1559 aanvaar is op die eerste nasionale Sinode van Parys. Hierdie geloofsbelydenis is die werk van Calvyn, wat die eerste ontwerp opgestel het. Daarna is dit hersien deur Antoine Chandieu, 'n leerling van Calvyn, wat saam met die Sinode die finale teks vasgestel het. Hierdie belydenis, getiteld Confessio Gallicana is in 1560, met 'n voorrede, by Ambois aan Koning Francois II aangebied. Beza het in 1561, by die godsdiensgesprek te Poissy, dit ook aan Charles IX aangebied. Die belydenis is in 1571 hersien en weer vasgestel by die Sinode van La Rochelle.

Die Confessio Gallicana, wat uit twee uitgawes bestaan, één met vyf en dertig en ' $n$ ander met veertig artikels, is 'n sorgvuldige samevatting van die Calvinistiese leer. De Brès, wat die NGB opgestel het, is daarin bygestaan deur Adrianus Saravia, Herman Moded en $G$ van Wingen. Dit is verder hersien deur Franciscus Junius van Bourges, voordat dit finaal in 1561 gepubliseer is. Dit is egter duidelik dat De Brès die hoofaandeel in die werk gehad het. Die NGB met sy sewe en dertig artikels volg die Confessio Gallicana, maar is uitgebrei ten opsigte van die Drie-eenheid, die vleeswording, die kerk en die sakramente. Daarby is dit opvallend dat die NGB minder polemies is as die Confessio Gallicana, hoewel dit skerp afgrens enersyds teenoor die Rooms-Katolieke Kerk en andersyds teenoor die Dopers en die radikales.

Dit is belangrik om daarop te let dat in 1566 die adel in Nederland in verset kom teen die Rooms-Katolieke onderdrukking. Die adel wil dan saam met die Hervormde kerkrade werk om die Spaanse juk af te werp. Vir dié doel is 'n Sinode te Antwerpen belê om saam met die adel te werk aan ' $n$ wysiging van die belydenis. Dan word, met die hulp van Junius, artikel 36 geformuleer soos dit tans daar uitsien. 
So word die belydenis, soos Paul Jacobs opmerk, 'of truly fundamental importance for the history of the founding of the Netherland State, because the formation of this state was a history of faith. The faith that was basic to this Confession enabled the nobles to form an alliance, and the Reformed Christians from Antwerp to Wesel to unite'. Die Nederlandse Geloofsbelydenis word, na 'n paar inleidende artikels oor die openbaring, gekenmerk deur sy beskouing van die Bybel. So stel artikel 7: 'Ons glo dat hierdie heilige Skrif die wil van God volkome bevat en dat alles wat die mens moet glo tot saligheid, genoegsaam daarin geleer word....'

Die Skrif alleen is dus die enigste kenbron van die waarheid en daaraan mag niks toegevoeg of iets daarvan weggelaat word nie. As die Skrif die enigste openbaringsbron is, dan wil die Geloofsbelydenis ook aansluit by die leer van die vroeë kerk en daarom word in artikel 9 gestel: 'Daarom aanvaar ons in hierdie opsig graag die drie belydenisse, naamlik dié van die Apostels, Nicea en Athanasius, en ook wat die ou vaders in ooreenstemming hiermee besluit het.'

Daarna stel die Geloofsbelydenis die sentrale momente van die leer van God se verlossende werk in Jesus Christus (art 12-21). Die besef dat Jesus Christus die enigste Middelaar is (art 26) bepaal die belydenis ten opsigte van die kerk (art 27. 29) waar duidelik teen die Anabaptisme afgegrens word. Die kenmerke van die ware kerk word ook genoem (art 29): 'Die kenmerke om die ware kerk te kan uitken is die volgende: dat die kerk die evangelie suiwer preek; dat dit die sakramente suiwer bedien, soos Christus dit ingestel het; dat dit die kerklike tug gebruik om die sondes te straf.'

Duidelik Reformatories is die Belydenis as gesề word dat die geloof alleen regverdig (art 22-23): 'Ons glo dat die Heilige Gees ons die ware kennis van hierdie groot verborgenheid laat kry. Hy laat daarvoor in ons hart 'n opregte geloof ontvlam wat Jesus Christus met al sy verdienste aanneem en wat ons Hom vir ons laat toeëien en wat ons niks anders meer buite Hom laat soek nie.'

Hierdie genade van God heilig die persoonlike lewe (art 24-25), die kerklike lewe (art 30-35) en die openbare lewe (art 36), en gee die toekomsverwagting (art 37). Opmerklik is die positiewe waardering van die owerheid, as dienaar van God, dit veral teen die Wederdopers.

Literatuur wat hieroor nagelees kan word is:

Bosman, H L ea 1987. Die Nederlandse Geloofsbelydenis - ontstaan, Skrifgebruik en gebruik. Pretoria: UNISA.

Cochrane, A 1966. Reformed Confessions of the 16th Century. London: SCM.

Schaff, P 1919. The Creeds of Christendom with a history and critical notes. New

York: Harper \& Brothers Publishers. 


\subsection{Staatkundige ontwikkelinge}

In 1555 het Keiser Karel V as keiser afgetree en sy troon aan sy seun Filips II van Spanje oorhandig. Filips II wat 'n fanatiese Rooms-Katoliek was, het met groot strengheid teen alle ketters in sy ryk opgetree.

In die Nederlande het Filips, met die medewerking van Pous Paulus IV, in 1559 die aantal Rooms-Katolieke bisdomme sterk vermeerder. Daar was nou drie Aartsbiskoppe, dié van Utrecht, Mechelen en Kamerijk en vyftien biskoppe. In elke bisdom was daar twee Kannunike wat voltyds besig was met geloofsondersoeke. Die nuwe aartsbiskop van Mechelen was Antonius Perreirot, maar hy word spoedig opgevolg deur Kardinaal Grenvelle. Grenvelle laat die Inkwisisie voltyds werk om die verspreiding van die Calvinisme teen te gaan. Die instelling van hierdie nuwe bisdomme het selfs by die Rooms-Katolieke volk teenstand verwek, ook omdat dit as inbreuk op ou regte en privilegies gesien is. Die hoë adel het deur hulle invloed in die kapittels, baie seggenskap in die benoeming van die hoë geestelikheid gehad. Maar nou is hulle regte hierin ingekrimp omdat aan die Koning baie mag gegee is by die benoeming van die biskoppe en kanunnike. Verder sou die kerkvorste, omdat hulle in al die state groot besittings het, se mag in die verskillende geweste nou toeneem en dit was vir die adel nie altyd aanvaarbaar nie. Die biskoppe wat daar was, was ontevrede omdat hulle bisdomme nou kleiner en hulle seggenskap beperkter geword het. Die Prins van Oranje wat Stadhouder van die provinsies Holland, Zeeland en Utrecht was, het hom met ander lede van die Raad van state in die opposisie bevind en word die erkende leier van hierdie groep. In sommige geweste t was daar van die begin af verset teen hierdie maatreël, veral in die noordelike provinsies van Friesland, Groningen en Overijsel. Die benoemde biskop van Deventer is nooit daar gewy nie en die biskop van Friesland het nooit eers die geleentheid gekry om sy bisdom te sien nie. Die benoemde biskop van Leeuwarden het eers in 1570 daar aangekom, terwyl die benoemde biskop van Roermond eers in 1568 sy amp aanvaar het.

Met die kerklike struktuur nou oorgehaal om op te tree, is die verskillende plakkate ( = owerheidsproklamasies) teen die ketters sorgvuldig toegepas. Dit beteken dat baie martelare ter wille van hulle geloof op die brandstapels sterf. Dikwels is die ketters eers so tereggestel nadat hulle ondervra en gemartel is deur die kerklike inkwisiteurs. Die kerklike inkwisiteurs wou die gevangenes oorreed om hulle kettery af te sweer, maar het nie juis daarin geslaag nie.

Die skerp vervolgings het die verset aangewakker en dit is opvallend dat die adel nou ook na vore begin kom. Dit bring mee dat kardinaal Granvelle, wat die hoogste kerklike en staatkundige gesag in Nederland beliggaam, in 1564 uit Nederland moet vertrek en vervang is deur 'n Landvoogdes. In hierdie tyd kom Prins Wil- 
lem van Oranje, die Stadhouder van Holland, Zeeland en Utrecht, al meer op die voorgrond as die leier van die verset. Oranje wil hê dat die owerheid vryheid van gewete moet toelaat, die geloofsvervolging moet beëindig en in sommige dele van die land selfs die vrye uitoefening van die godsdiens moes toelaat. Hier het hy waarskynlik aan die Duitse kompromis-'oplossing' van die cuius regio eius religio gedink. Op hierdie punt het die Nederlandse Calviniste egter ' $n$ lastige struikelblok gevorm, want hulle was nie baie geneë om ingepas te word in die Duitse struktuur nie. Hoewel daar Calviniste was wat nie groot besware het teen die aanvaarding van 'n Lutherse belydenisskrif soos die Confessio Augustana nie, want dit sou ook weer politieke voordele kan meebring, slaag die gedagte nie. Dit misluk ook omdat die klein groepies Lutherane geen verwantskap met die Calviniste voel nie. Die Lutherane het nie die Calvinistiese Nagmaalsleer aanvaar nie en wou onder geen omstandighede optree teen die owerheid nie. Daarby het Matthias Flacius Illyricus, 'n strydvaardige Lutheraan, die verskille met die Calvinisme so skerp gestel, dat daar ook nie juis sprake kon wees van 'n samegaan nie. Daarby verminder die Lutherse invloed as die Lutherane in Nederland, onder druk van die vervolging, geleidelik die land verlaat.

Die Calviniste het, anders as die Lutherane, optrede teen die owerheid wel aanvaar. In die voetspoor van Calvyn sien hulle opstand teen 'n dwalende, onderdrukkende owerheid as volkome regverdig wanneer die laer owerhede die leiding in so 'n verset neem. In Nederland wou die hoë adel nie so ver gaan nie, maar die laere adel het wel daarvoor kans gesien. Een van die leiersfigure hier word Prins Lodewyk van Nassau, 'n broer van Oranje wat 'n oortuigde Calvinis is. Hy versamel ' $n$ groep van die laere adel rondom hom, wat sowel met die Calvinistiese kerkrade as verskillende vooraanstaande figure uit die handel- en koopwêreld skakel - laasgenoemde omdat hulle bereid was om die nodige finansiering te doen.

Nadat die hoê adel eintlik weier om op te tree, het die laere adel op 5 April 1566 'n smeekskrif by die Landvoogdes, Margaretha van Parma, ingedien waar gevra word dat die inkwisisie opgehef moes word. Terselfdertyd het hulle gevra dat die koning se proklamasies teen kettery ingetrek moet word en dat die Staten-Generaal oor die godsdienstige beleid van die land moet besluit. Margaretha wou nie toestem tot die versoek nie, maar het wel 'n soort 'skietstilstand' voorgestel waartydens die vervolginge gestaak wou word. Hierdie Verbond der Nederlandsche Edelen het, naas Lodewyk van Nassau as leierfiguur Phillips van Marnix, Heer van St Aldegonde (1540-1598) gehad. Phillips van Marnix was een van die bekendste Calviniste in Nederland. Hy was 'n veelsydige geleerde, staatsman en kerkman wat in Genève aan die universiteit aldaar studeer het. 
In die Nederlandse verset teen die Spaans-Roomse owerheid speel hy 'n groot rol. Allereers het hy die Verbond der Edelen help oprig, maar daarnaas ook baie gedoen om deur die Calvinistiese kerkrade ' $n$ hegte organisatoriese versetnetwerk op te bou. As Willem van Oranje die leier van die verset word, is Phillips een van sy naaste medewerkers.

Op kerklike vlak het hy in 1580-1591 'n eie Psalmberyming die lig laat sien. Hoewel dit van beter kwaliteit is as die een van Datheen, kan sy Psalmberyming nie Datheen se werk verdring nie. Hy word oor die algemeen beskou as die digter van die volkslied, Wilhelmus van Nassouwe, wat die strydlied van die verset word. Sy beroemdste geskrif is sy satiriese aanval op die Rooms-Katolieke Kerk, te wete De Biencorf, wat in 1569 verskyn. Daarnaas het hy nog verskillende ander belangrike geskrifte geskryf. In sy laaste jare woon hy in Leiden waar hy aan 'n Bybelvertaling werk - 'n werk wat hy egter nooit voltooi het nie.

Die Smeekskrif van die adel het geen uitwerking gehad op die beleid van die owerheid nie en die vervolging van alle nie-Rooms-Katolieke gelowiges het toegeneem. Tog het die Smeekskrif 'n belangrike resultaat gehad, omdat dit die verset verstewig het en al meer mense gedwing het om 'n standpunt in te neem ten opsigte van die onderdrukkende beleid wat gevoer is.

\subsection{Die kerklike verset neem toe}

Die Verbond der Edelen en die toenemende druk van die vervolginge het ook reaksie in die hand gewerk. Nie alleen word Calvinistiese pamflette nou op groot skaal versprei nie, maar ook Rooms-Katolieke priesters, wat met die Hervorming simpatiseer, spreek hulle gevoelens openlik van die kansel uit. So is Cornelis Huberti in 1565 gearresteer vanweë sy preke, terwyl 'n ander priester in Maastricht in sy preke uitgevaar het teen 'die gebakte god', 'n verwysing na die Rooms-Katolieke leer van die transsubstansiasie van die Nagmaalelemente. Hy het ten ene male ontken 'dat ons Here in brood kan ingaan',

Margaretha van Parma, die landvoogdes, se aanbod om die vervolging tydelik te staak, het beteken dat baie vlugtelinge nou terugkeer na Nederland. Die hoë verwagtings wat gekoester word, lei tot allerlei nuwighede. So gebeur dit dat 'n jong monnik, Carolus Daneel, uit die klooster wegloop en dan in die omgewing van Ijperen in die opelug begin preek in Mei 1566.

Betreklik gou het hy met sy prediking buite die stad in die oop veld gehore van meer as 'n duisend mense getrek. Ander volg sy voorbeeld en so ontstaan die verskynsel van hagepreeken. Dan gee die verskillende kerkrade aan hulle predikante opdrag om ook so in die opelug te preek. Gou het die hagepreke 'n massa-beweging 
geword waaraan nie net die gewone mense deelgeneem het nie, maar ook hooggeplaastes en lede van die adel.

Dan begin die Calviniste eis dat hulle in die stede godsdiensoefeninge wil hou. Waar dit geweier word, het hulle met geweld hulle wil deurgevoer. So gebeur dit dat vier predikante in Brugge in die kerk preek. As die magistrate beswaar maak, verlaat hulle die kerkgebou en sit hulle prediking langs die gebou voort. Geleidelik het die klimaat al meer anti-Rooms geword. In Mei 1566 het 'n jong man tydens 'n misbediening in die kerk te Oudenaerde, die skottel met brood uit die hand van die priester geruk en gesê dat dit niks meer as brood is nie en dat die verering daarvan afgodediens is. In Julie word al berigte gehoor dat kerke en kloosters geplunder word. Dan ontplof dit in Augustus in Vlaandere, naby die Franse grens, waar kerke binnegeval word en alle beelde, die altare en die orrels verwoes word. In Antwerpen is gedurende Augustus ongeveer dertig kerke so gestroop. Dieselfde gebeur in Gent en ander stede.

Hoewel dit nie meer vasgestel kan word watter rol die predikante in die beelde. storm gespeel het nie, is dit wel waar dat die predikante nou die geleentheid aangegryp het om die Calvinistiese godsdiensoefening te vestig as die normale. In baie stede en dorpe eis die predikante nou om in die verwoeste katedrale te mag preek.

In Augustus 1566 publiseer Margaretha, die landvoogdes, ' $n$ Accoord. Daarin word aan die Calviniste vryheid en veiligheid gewaarborg as hulle godsdiensoefeninge hou op diế plekke waar hulle dit tot dusver gedoen het. Maar dan mag hulle niks doen om Rooms-Katolieke byeenkomste te hinder nie. Daarmee het Margaretha bedoel dat die Calviniste nèt buite die stede in die opelug mag preek, maar dat die Rooms-Katolieke Kerk sy regte en voorregte binne die stede en dorpe sou behou. Indien die Calviniste egter in die stede en dorpe die sakramente sou bedien, huwelike bevestig, onderwys gee en armversorging behartig, dan sou hulle inbreuk maak op die regte van die Rooms-Katolieke clerus en die magistrate. Aanvanklik was dit nie duidelik presies wat die Calviniste as doelwit gehad het nie.

In die meeste stede vra die Calviniste nou die reg om in die stede en dorpe te preek. In sommige gevalle bou hulle hulle eie kerke, in ander plekke neem hulle die Rooms-Katolieke kerke oor. Sommige van die bewindhebbers was bekommerd dat die Calviniste nie tevrede sou wees met die reg om te preek nie, maar dat hulle kerk en stad sal wil beheer, soos in Genève.

Dit word geleidelik duidelik dat sommige Calvinistiese predikante wel ambisies het om nie net die kerk te hervorm nie, maar om ook die stadsbesture oor te neem. Vroeg in Oktober is selfs 'n sinode in Gent gehou waar besluit is om drie miljoen gulden in te samel om daarmee godsdiensvryheid by Filips II te koop. Uiteindelik is die geld gebruik om troepe in Duitsland te huur om die Hervormers teen Filips II te 
beskerm. Intussen het die predikante in al meer stede eise begin stel om daar die sakramente te bedien.

Margaretha, die landvoogdes, het intussen ook meer troepe tot haar beskikking gekry en begin om garnisoene in verskillende stede te plaas om sodoende die magistrate te help om die druk van die Calviniste te weerstaan. So gebeur dit dat verskillende stede, wat deur die Calviniste oorgeneem is, deur Margaretha se troepe beleër word. So word onder andere Valenciennes beleër omdat die predikante en die stadsinwoners weier om 'n garnisoen daar te aanvaar. Terwyl Valenciennes standhou, is daar ander stede wat die voorbeeld volg en in die winter van 1566-1567 word vyf stede deur regeringstroepe beleër. In Maart 1567 word 'n Protestantse leër egter verslaan en aangesien prins Willem van Oranje nie wil beweeg nie, moet die vyf stede kapituleer. Dit is vanweë hierdie kapitulasie dat onder andere Guido de Brès gevange geneem en daarna opgehang word.

Nou gryp Filips II self in en in Augustus 1567 kom die hertog van Alva, Filips se bekendste generaal, in Nederland aan saam met sy troepe. Filips het aan Alva as landvoog ' $n$ vrye hand gegee om op te tree. Hoewel Willem van Oranie in sy beroemde Verantwoording daarop wys dat die onderdrukking die verset uitgelok het, het dit geen sigbare effek nie.

Dit is dan duidelik dat Filips II 'n beleid van onderdrukking wil volg. Baie Calviniste en ander Hervormingsgesindes verlaat dan die land. Die vlugtelinggemeentes in die Rynstreek, in Oos-Friesland en Engeland het meeste van hierdie mense herberg gegee. Selfs Willem van Oranje verlaat in April 1567 die land en gaan voorlopig na sy familie in Duitsland. Alva stel onmiddellik, nadat hy die bewind oorgeneem het, die sogenoemde Raad van Beroerten, of Bloedraad in wat deur middel van teregstellings en verbeurdverklarings die veldtog teen die Protestantisme voortsit. As gevolg van die optrede van die Bloedraad het tussen 6000 en 8000 martelare die lewe gelaat. Die Hertog van Alva wou deur middel van sy Bloedraad die Rooms-Katolieke kerklike reorganisasie deurvoer, die besluite van die Konsilie van Trente afdwing en op staatkundige en finansiële gebied Nederland al nouer aan Spanje koppel.

Alva se skerp onderdrukkende maatreëls maak 'n openlike opstand nou vanselfsprekend. 'n Eerste poging tot militêre verset eindig egter in 'n neerlaag van die leërs van Lodewijk van Nassau in 1568. 'n Poging van Willem van Oranje om die land met 'n leër in te val, misluk ook, sodat net die Water- en Bosgeuse die stryd volhou. Die verloop van die stryd verander as die Geuse op 1 April 1572 Den Briel bevry en dan verower Lodewijk die stadjie Bergen. 
Literatuur wat geraadpleeg kan word, is:

Crew, P M 1978. Calvinist preaching and iconoclasm in the Netherlands 1544-1569, Cambridge: CUP.

Habsburg, O 1967. Karl V. Wien: Verlag Herold.

Wittemans, F (red) sj. Mamix van sinte Aldegonde. Brussel: Uitgeversmaatschappij Onze Tijd. 